Digilec 6 (2019), pp. 1-13

Fecha de recepción: 25/12/2019

Fecha de aceptación: 26/02/2020

DOI: https://doi.org/10.17979/digilec.2019.6.0.5893

\title{
EL TRATADO JARDÍN DE NOBLES DONCELLAS Y SU INFLUENCIA EN LA PERSONALIDAD DE ISABEL LA CATÓLICA
}

\author{
THE TREATISE JARDÍN DE NOBLES DONCELLAS AND ITS \\ INFLUENCE ON THE PERSONALITY OF QUEEN ISABELLA THE \\ CATHOLIC
}

\author{
Vanesa REGALADO DEL VALLE* \\ Universidad Nacional de Educación a Distancia (UNED)
}

\section{Resumen}

En la tratadística de la segunda mitad del siglo XV, en los reinos de Castilla y de León, observamos una corriente muy interesante, la de tratados y escritos dirigidos a la formación de los jóvenes, especialmente a los infantes e infantas destinados a ocupar un lugar en monarquías propias o ajenas. Así, en este contexto, surge la obra central de este artículo, el tratado educacional Jardín de nobles doncellas de fray Martín Alonso de Córdoba (Martín de Córdoba), y dirigido a la que se convertiría en la Reina Isabel I (Isabel La Católica tras 1496). Como veremos a lo largo de estas líneas, este tratado no solo poseía una vertiente formativa; sus lecciones iban más allá del mero aprendizaje. ¿Podríamos decir que este tratado influyó en la forma de actuar y gobernar de la futura Reina Isabel? Poco a poco lo iremos descubriendo en este estudio.

Palabras clave: Isabel la Católica; siglo XV; propaganda política; "specula reginae”; Martín de Córdoba

\begin{abstract}
Regarding the original sources in the second half of the 15th century in the Kingdoms of Castile and Leon, we observe a very interesting trend, related to treatises and writings intended for youth training, especially for the infantes and infantas, who were meant to hold a ruling post in their own country or abroad. In this context, the text analysed in this article emerges, the educational treatise Jardín de nobles doncellas by Fray Martín Alonso de Córdoba (Martín de Córdoba), which was addressed to the person who would became Queen Isabella of Castile (Isabella the Catholic from 1496 onwards). As we will see all along this article, this treatise not only had a training approach but its lessons went beyond the mere educational purpose. Could we say that this treatise had any influence in the future queen's way of acting and ruling? We will discover it in the following study.
\end{abstract}

Key Words: Isabella the Catholic; $15^{\text {th }}$ century; political propaganda; “specula reginae”; Martín de Córdoba 


\section{INTRODUCCIÓN}

En este artículo abordaremos los rasgos de la personalidad de Isabel La Católica a través de una fuente coetánea muy interesante: el tratado doctrinal Jardín de nobles doncellas (1468-1469) escrito por el religioso agustino Martín de Córdoba (+ 1476), y dirigido a la princesa Isabel, antes del ascenso al trono.

Esta fuente se engloba dentro de una "corriente pretendidamente profeminista" (Rábade Obradó, 2005: 65), esto es, que exalta las cualidades femeninas respecto a la tradición tratadística anterior que, en líneas generales, exhortaba los defectos de las mujeres. Sin pretender en este artículo ahondar en un examen pormenorizado de ambas corrientes, sí que se considera fundamental encuadrar esta fuente en el contexto social y literario que, en esos momentos, brotaba en la corte objeto de este estudio, la Corte de los reinos de Castilla y de León.

Resulta curioso destacar que la obra de este fraile agustino "no estuvo entre las que coleccionó Isabel La Católica, o al menos no lo estaba cuando se efectuó el primer inventario de su biblioteca” (Rábade Obradó, 2005: 63). No obstante, acercándonos poco a poco a esta fuente, observaremos matices y cualidades que en ella se destacan como imprescindibles para una buena gobernante, y que serán tónica general en el comportamiento, en las decisiones y, por ende, en el modo en que Isabel reinará y gobernará la Corona de Castilla ${ }^{1}$. Estas afirmaciones se refrendarán con otros escritos y crónicas contemporáneas a la Reina Isabel, que iremos desgranando en estas páginas.

\section{SOCIEDAD BAJOMEDIEVAL COMO TIERRA FÉRTIL PARA VISIONES RENOVADAS}

La alta sociedad medieval se desarrollaba como un gran escenario, donde ver y ser visto. Cada personaje en la Corte desempeñaba un papel, y no uno cualquiera, sino el papel que a cada uno se le había otorgado desde la cuna, esto es, aquel que la sociedad esperaba de él o de ella en función de su rango y clase social. El ambiente cortesano se presenta así como el escenario ideal donde desarrollar todas y cada una de las funciones sociales.

Entre los aspectos más relevantes de esta época, nos topamos con el ideal del amor cortés, el "ethos cortesano, muy en sintonía con esas aspiraciones humanistas que comienzan a cobrar fuerza en el continente europeo” (Peláez, 2013: 267). Es decir, hombres y mujeres de alta cuna con exquisita formación y refinamiento, que disfrutan juntos de actividades de ocio como la música, las artes, pero también los juegos, entre los que el ajedrez ocupa un interés predominante. Es importante insistir en la plasmación de

\footnotetext{
${ }^{1}$ En documentos oficiales, por regla general, se especifican todos y cada uno de los reinos, señoríos y condados propiedad de la Reina Isabel. No obstante, a la hora de acotar, se reducen a los reinos de Castilla y de León como reinos cabecera. En cuanto a reseñas propias de la Corona, se han localizado numerosas referencias a la Corona de Castilla como aglutinadora de todos los reinos, en distintas crónicas coetáneas. Así, en este artículo, se utilizarán estas dos expresiones, cuando sea necesario referirse a reinos y a Corona.
} 
esa escenografía cortesana, en la que reyes, infantes, personal de la corte y nobleza se desenvolvían a la perfección, con sus intrigas, sus apariencias y sus juegos de amor y de poder. Y la princesa Isabel se crio en ese ambiente; aun viviendo su infancia en las burbujas sacralizadas de las residencias de Madrigal y Arévalo con su madre y su hermano, fue consciente de todas estas vicisitudes propias de la Corte, aún más refrendadas y acrecentadas cuando pasó al Alcázar de Segovia bajo la custodia de su hermanastro Enrique IV.

Isabel aprendió a medir perfectamente los tiempos y a utilizar todas las armas de las que disponía para su propio beneficio. Las crónicas oficiales la describen como una mujer piadosa y recta ${ }^{2}$, pero, tras su acceso al trono y en el desarrollo de su reinado, queda patente su gran habilidad política y, sobre todo, su gran capacidad de estrategia (tanto la suya como la de sus más íntimos colaboradores).

Aún sin haber colocado la corona de Castilla sobre su "rubia”3 cabellera, ya había articulado a su alrededor un entramado propagandístico que, sin duda, fue uno de sus grandes aciertos durante todo el reinado. Y este texto de Martín Alonso de Córdoba podría formar parte, tal y como veremos más adelante, de ese armazón forjado para su gloria y ensalzamiento que, aún sin haber sido coronada, ya estaba en funcionamiento.

\section{BREVE RESEÑA BIOGRÁFICA DEL TRATADISTA MARTÍN DE CÓRDOBA}

Poco sabemos del inicio vital de este fraile agustino. Por su apellido, parece claro que nació en Córdoba, profesando la vida religiosa en dicha ciudad. Encontramos referencias hacia 1420, cuando ingresó en el convento de San Agustín de Salamanca. Fue un prolífico estudiante, obteniendo diversos grados en Zaragoza y Salamanca (en la que además ejerció como catedrático de Teología y Filosofía Moral). Asimismo, ejerció como profesor en la Universidad de Toulouse.

Su amplia formación y experiencia académica favoreció su posición en la corte de Juan II de Castilla y de León. De esta pasó a la corte de Enrique IV, donde se ocupó principalmente de la formación del infante Alfonso. Así, encontramos a Martín de Córdoba ofreciendo su apoyo en la causa alfonsina durante los años de contienda con el rey Enrique IV y, a la postre, continuó su filiación al linaje de la familia brindando posteriormente su apoyo a la princesa Isabel, de la que se sabe recibió su formación en su juventud (entre los 15 y los 17 años).

Otra de las creaciones literarias de Martín de Córdoba está dedicada al condestable D. Álvaro de Luna, figura clave en el reinado de Juan II de Castilla y de León, que consiguió aglutinar tanto o más poder que el propio monarca. A este personaje dedicó Córdoba el tratado Compendio de la fortuna (en dos libros, 1440-1453).

\footnotetext{
${ }^{2} \mathrm{Al}$ respecto, es importante destacar que las crónicas oficiales no destacan por su objetividad; al fin y al cabo se escribían para ensalzamiento del homenajeado o para detrimento de sus enemigos

${ }^{3}$ Así define Hernando del Pulgar su color de pelo, en la Crónica de los Reyes Católicos.
} 


\section{SOBRE EL TRATADO JARDÍN DE NOBLES DONCELLAS}

Así, en el contexto social anteriormente descrito de la Corona de Castilla, surge este tratado educacional Jardín de nobles doncellas. Martín de Córdoba le debió hacer entrega a Isabel de este compendio en torno a la Concordia de Guisando (1468), donde la posición de la infanta quedó altamente reforzada como legítima sucesora y futura propietaria de los reinos de Castilla y de León. Por aquel entonces parecía claro que el devenir de la Corona de Castilla era estar regida por una mujer; por tanto, no había mejor forma para legitimar este hecho que escribiendo un tratado realzando las cualidades femeninas, pero sin dejar de lado sus flaquezas (de necesaria superación).

Este tratado se enmarca en una doble vertiente; la primera, anteriormente indicada, una corriente profeminista. La llamada querelle des femmes o querella de las mujeres fue un debate que surge en los rescoldos medievales, en la cual que se defendía la capacidad intelectual y política de la mujer. Pero también encontramos en la obra tonos del llamado "speculum reginae" ${ }^{4}$, o aquellos tratados educativos destinados a la formación de futuros gobernantes.

Asimismo, se hace necesario formar a la futura reina para que eduque a sus siervos, especialmente a las mujeres ${ }^{5}$, siendo espejo de las virtudes cristianas (eje fundamental de este tipo de tratados) y, por lo tanto, fuente de sabiduría en la que beben el resto de doncellas que a sus órdenes se encuentran ${ }^{6}$. Asimismo, en palabras de Carrasco Manchado, se trataría "del primer intento literario de propaganda legitimadora de la futura Isabel La Católica” (Rábade Obradó, 2005: 67). Es más, otros autores sostienen que este tratado no solo sería un escrito pro-isabelino sino también anti-enriqueño, es decir, en contra del aún imperante reinado de Enrique $\mathrm{IV}^{7}$.

Este último enfoque resulta muy interesante, porque entroncaría con ese ideal reivindicativo de su linaje por parte de Isabel $^{8}$, frente al problema sucesorio planteado por Enrique IV: ensalzar a la legítima sucesora mediante "una breve escritura que hable de la generación e condición, composición de las nobles dueñas; en especial de aquellas que son o esperan ser reinas” (Córdoba, 1964: 68) ${ }^{9}$. A lo largo de las páginas de su tratado,

\footnotetext{
${ }^{4}$ Esta modalidad de tratados son prolíficos en la época. Encontramos otros ejemplos en los dedicados a la infanta Isabel, primogénita de los Reyes Católicos (Criança y virtuosa dotrina de Pedro Gracia Dei, ca. 1486), o en la formación del único varón del matrimonio, el príncipe Juan, a quién Alonso Ortiz le dedicó el tratado Diálogo sobre la educación del Príncipe don Juan.

${ }^{5}$ Este aspecto era tradicionalmente notorio en las reinas consortes, entre cuyas funciones se encontraba la de formar a las doncellas de la Corte.

${ }^{6}$ En este sentido, la pretendida relación entre la Virgen María y la figura de Isabel se realiza de forma consciente y con un absoluto papel propagandístico a lo largo de todo su reinado.

${ }^{7}$ En este sentido, destacar a Soriano del Castillo (1997: 1462).

${ }^{8}$ Esa reivindicación no solo la observamos a través de la palabra escrita. La apoteosis de la legitimidad del linaje isabelino, primero en la figura de su hermano y posteriormente en la suya propia, la encontramos en el monumento funerario en el que convirtió la Cartuja de Miraflores en Burgos, con los espectaculares monumentos funerarios a sus padres y a su hermano, y rematando el conjunto con un colosal retablo en el que las figuras de sus progenitores cobran especial relevancia. La propaganda llegaba a más personas (especialmente a las iletradas) mediante la representación arquitectónica y figurativa, ensalzando así logros y emblemas para más gloria de los homenajeados.

${ }^{9}$ Citado en Sánchez Dueñas (2002: 293).
} 
subyace la idea clara y rotunda de que las mujeres están perfectamente legitimadas para gobernar en nombre propio.

La obra se divide en tres partes, cada una de ellas a su vez en capítulos: nueve la primera y diez la segunda y la tercera. Así, en este esquema se nos presentan virtudes y vicios femeninos perfectamente estructurados con el fin de exhortar a la destinataria a que ensalce las primeras, minimizando los segundos.

No siempre este tratado ha sido bien aceptado por la crítica, ya que en numerosas ocasiones "ha sido estudiado en su mayor parte de manera muy fragmentaria, sin reflejar en su justo medio valor que este texto pueda representar” (Sánchez Dueñas, 2002: 293).

A continuación, desgranamos poco a poco las virtudes y vicios recogidos por Martín de Córdoba, y los trasvasaremos a la personalidad y gobierno de Isabel para corroborar o no la influencia de este tratado en ambos aspectos.

\subsection{Virtudes femeninas}

Como virtudes femeninas a intensificar, englobadas y resumidas en los siguientes epígrafes, encontramos:

- El amor y el temor a Dios: claro parece ser este aspecto en la personalidad de la reina: "La vida espiritual acrisolada y comprometida fue un hilo conductor en la vida de la soberana” (Azcona, 1999: 380).

- Cumplimiento de los ritos que impone la fe católica. Como única “fee verdadera" ${ }^{10}$, siendo así espejo de los fieles; incidiendo en este aspecto destacamos una analogía, pretendida en la época y en la concepción isabelina, en la que se relacionaba a la Virgen María e Isabel: al igual que la Virgen dio a luz a Cristo, Isabel debe dar a luz la palabra de Dios. Virgen como gestadora continua, albergando siempre a Jesús en su interior $^{11}$, relacionando esta cualidad con uno de los fines fundamentales de la Reina Isabel: ser portadora continua de la palabra cristiana.

La devoción no sólo correspondía a mujeres sin posición, sino “para reinas y princesas, rezar sus horas e devociones, oir sermones y palabra de Dios, hazer que lean delante dellas cuando comen, e quando están retraídas lecturas honestas e santas; conversar con letrados e sabios; pensar siempre en la otra vida e en la quenta que a de dar a Dios tan estrecha; hablar e oir de la gloria del Paraíso" (citado en Azcona, 1999: 388). El referido autor, asegura que estas palabras debieron causar mella en la reina, ya que instigó a Hernando de Talavera a que escribiese un libro sobre teología católica.

El cronista Diego de Valera redunda en esta cuestión incidiendo en el papel providencialista de la soberana y su comparativa con la Virgen: "bien se puede con verdad desir que así como Nuestro Señor quiso en este mundo nasciese la gloriosa Señora Nuestra e della procediese el universal redentor del linage humano, así determinó vos, señora, nasciésedes para reformar e restaurar estos reinos e sacarlos de la tiránica

\footnotetext{
${ }^{10}$ Así se refieren a la religión católica en documentos y crónicas de la época.

${ }^{11}$ En este sentido, una iconografía muy interesante es la que encontramos en el cuadro que cuelga en la Sala Capitular del Monasterio de las Huelgas en Burgos y que representa a la Virgen María embarazada (como gestadora continua) albergando bajo su manto a los Reyes Católicos y tres de sus hijos, al cardenal Mendoza y a un grupo de monjas cistercienses, entre ellas Leonor de Mendoza la hermana del cardenal.
} 
governación en que tan luengamente han estado” (Ladero Quesada, 1999: 144). Sin duda, reveladoras palabras para comprender y refutar ese halo promocionista que rodeaba (especialmente) la figura de la reina.

- Proteger la iglesia con limosnas, construcción de templos ${ }^{12}$, dotación de material para el culto, etc.: así fue, los libros de cuentas de la reina están repletos de limosnas a templos (como por ejemplo las ofrecidas para la celebración de las santas fiestas) ${ }^{13}$, y dotación de material para el culto (algunos de sus espejos, por ejemplo, donados y convertidos en custodias $)^{14}$. En el caso concreto de las limosnas, la actividad fue creciendo tanto, que fue necesario institucionalizarla nombrando un Limosnero Mayor de su Alteza, con fondos fijos, entresacados del presupuesto de la Casa de la Reina, y distribuidos, cerca y a lo lejos, por diversas personas de su casa y corte (Azcona, 1999: 389).

- Práctica de la castidad: Probablemente Martín de Córdoba apuntaló esta virtud (fundamental a lo largo del tratado) como estandarte del comportamiento de la princesa, para diferenciarla así del dudoso quehacer de la reina Juana de Avis. Por lo tanto, esta connotación de castidad, desde mi punto de vista, debe ser vista de esta manera y fundamentalmente aplicada a la época previa al matrimonio con Fernando II de Aragón, sin buscarle un trasfondo de abstinencia sexual durante su matrimonio.

Por un lado, la descendencia de los Reyes Católicos no admite lugar a dudas, y, por otro lado, según nos narran sus propios cronistas oficiales "Amaba mucho al rey su marido y celábalo fuera de toda medida” (Pulgar, s. XVI) ${ }^{15}$. Resulta más que evidente que una persona que presenta unos sentimientos tan vehementes por su pareja, no puede albergar demasiado atisbo de castidad durante su unión. En este aspecto, es importante destacar que en el tratado realizado por Alonso Ortiz y dirigido al infante Juan la castidad se toma como un aspecto secundario e incluso prácticamente inexistente entre las virtudes del hombre ${ }^{16}$.

- Mesura, sosiego, vergüenza: Son virtudes ampliamente recomendadas en todos los tratados sobre educación femenina. En este aspecto se recoge un interesante punto escrito por Ladero Quesada, en el que aglutina la opinión de los cronistas coetáneos al respecto: su autodominio se extendía a disimular el dolor en los partos, a "no decir ni mostrar la pena que en aquella hora sienten y muestran las mujeres” (Del Pulgar). “Templada y moderada en la risa" (Flores). "Y no fue la reina —añade Sículo— de ánimo menos fuerte para sufrir los dolores corporales ... $\mathrm{Ni}$ en los dolores que padecía de sus enfermedades, ni en los del parto, que es cosa de grande admiración,

\footnotetext{
${ }^{12}$ El Monasterio de San Juan de los Reyes es un claro ejemplo de propaganda isabelina.

${ }^{13}$ Se puede ejemplificar este aspecto con un documento custodiado en el Archivo General de Simancas y en el que se detalla una ofrenda por la festividad de Navidad de 29 doblas de oro (=15.080 mrs.). Signatura: CCA,CED,4,46,4).

${ }^{14}$ En la Capilla Real de Granada encontramos una de estas donaciones.

${ }^{15}$ Curiosa, sin duda, esta descripción del exceso de celo de Isabel realizada por uno de sus cronistas oficiales.

${ }^{16}$ Versión bien diferente nos ofrece Pedro de Luján en sus Coloquios matrimoniales (1550), que se trata de una fuente posterior pero que recoge ampliamente la nueva corriente surgida al final del Medievo, donde afirma: "el hombre onrado especial el que es casado debe huir de contratos de rameras y aún de tratos de alcahuetas. Que paz puede tener en su casa el hombre que tiene amiga. En la ley de Christo la fidelidad que deve la muger al marido esa misma deve el marido a la muger”.
} 
nunca la vieron quejarse, antes con increíble y maravillosa fortaleza los sufría y disimulaba” (Ladero Quesada, 2006: 234). Lo que parece estar claro, según las crónicas de los escritores, es que la reina practicaba la continencia en sus emociones, especialmente en público siendo "prudente y de mucho seso" (Enríquez del Castillo, en Ladero Quesada, 2006: 237).

- Humildad, sencillez: "Profunda en consejo, fuerte en constancia, constante en justicia, llena de real clemencia, humildad y gracia”. Estos son los adjetivos con los que nos la describe Rodrigo Santaella, en la dedicatoria de su Vocabulario Eclesiástico de 1495 (Azcona, 1999: 375).

- Perpetuidad del linaje: Llegamos a una de las virtudes fundamentales atribuidas a las mujeres en general, y a las reinas, ya sean propietarias o consortes, en particular. Isabel sintió la gran necesidad de engendrar descendencia, fundamentalmente varones. Realmente, para la Corona de Castilla este aspecto no era relevante porque los reinos de Castilla y León admitían el gobierno de la mujer (su figura era el mejor ejemplo); el problema surgía en Aragón, donde las mujeres tenían prohibido gobernar la Corona en propiedad (lo que trajo más de un quebradero de cabeza a Fernando el Católico con las Cortes aragonesas en tiempos).

- Dedicación a su marido y a sus hijos: Este punto es totalmente comprobable en todas y cada de las crónicas sobre su reinado, e incluso en las diferentes fuentes primarias (cartas, etc.) que se conservan en los archivos estatales. Su concepción de cómo debía ser una reina incluía su dedicación plena al rey (por aquello también de afianzar la empresa conjunta que habían emprendido) y su completa dedicación a sus hijos, especialmente al único hijo varón que sobrevivió al parto y por cuya muerte la reina padeció grandes sufrimientos ${ }^{17}$.

En este sentido, es curiosa la posición que, según Córdoba, debe adoptar la mujer, ni señora ni sirvienta del marido, sino compañera: “A esto digo que fue asi hecho por mostrar que se criava en compañía de amor e dilexion de su marido, que si Dios la criava de la cabeça del varón pasresciera que la hazia como su señora, e si la criara de los pies paresciera como que la criava para servienta del varon; pues quanto se hazia no por ser señora ni sirvienta suya, mas para ser su compañera en matrimonio” (Sánchez Dueñas 2002: 294). Entronca así con lo que Pedro de Luján desgrana unos ochenta años después, a tenor de los coloquios entre su mujer casada y su doncella: "el marido es el espejo de la muger y la muger del marido, pues si el que mira al espejo está triste está el espejo”.

Martín de Córdoba mantiene el papel de la mujer como moneda de cambio en los litigios entre reinos: "acaece que han contienda los grandes señores sobre partimiento de tierras e lugares, e con una hija hacen paz, travan parentesco” (en Sánchez Dueñas 2002: 295). Esta máxima resulta aún más aplicable y recomendable al alto estrato social, especialmente si hablamos de la monarquía; Isabel educó así a sus hijas y decidió (en consonancia con su marido) el futuro de las mismas mediante enlaces matrimoniales ventajosos para las Coronas de Castilla y de Aragón. Los Reyes Católicos manejaron a la

\footnotetext{
${ }^{17}$ En la narración del fallecimiento de la reina, el cronista Andrés Bernáldez nos narra "murió [...] de gloriosa memoria en el mes de noviembre año 1504 [...] de dolencia e muerte natural que se creyó recrecérsele de los enojos e cuchillos de las muertes del Príncipe Don Joan, de la reyna de Portogal, Princesa de Castilla, sus hijos, que traspasaron su anima y su corazón”.
} 
perfección los pactos nupciales de sus hijos con la clara intención de afianzar o conseguir alianzas y/o aislar enemigos.

- Modestia en el vestir evitando lujos desmedidos; Este es un rasgo fundamental en la leyenda que se ha creado en torno a la figura de la Reina Isabel. El propio Córdoba nos aporta la puntualización de “evitando lujos desmedidos”. Parece poco probable considerar que cualquier rey o reina de la época (o de cualquier otra) no usase todo el boato para escenificar su poder, tanto a su corte como a sus visitantes, y la Reina Isabel no iba a ser menos. En crónicas están narrados los dispendios realizados para el bautizo del infante Juan, la celebración de la conquista de Granada o las sedas y joyas que recogen las cuentas de Gonzalo de Baeza en el inicio del siglo XVI. Ni qué decir tiene el manido tema del cambio de camisa, mito totalmente insostenible y refutable si se observan con calma las cuentas del tesorero real, en las que figuran partidas para la compra de cientos de camisas durante los años de contienda por Granada.

Ahora bien, sí podría ser cierto que la mesura en el vestir recomendada por Martín de Córdoba se llevaba a cabo en el día a día de la reina, en un entorno en el que no había que escenificar el aparato propagandístico para demostrar públicamente el poderío de la Corona. También es importante añadir que durante los primeros años del reinado, los reinos de Castilla y de León vivieron sumidos en la Guerra de Sucesión contra Portugal, que trajo más de un quebradero de cabeza a las cuentas de la Corona ${ }^{18}$, lo que sin duda, no propiciaría en demasía el dispendio en lujos no necesarios. Igualmente, con los fallecimientos de sus dos hijos y dos de sus nietos desde 1497, el ánimo y la salud de la reina se vieron seriamente afectados, por lo que no habría excesiva cabida para el dispendio superfluo en la vida de la reina ${ }^{19}$.

No obstante, al mismo tiempo que el agustino invocaba la modestia en la vestimenta, advertía como error el excesivo pudor en las vestimentas, “pues tan erróneo es aparentar lo que no se es como no representarlo” (en Sánchez Dueñas, 2002: 296). Sin duda, se trataba de buscar un equilibrio entre ambos extremos que, desde mi punto de vista, fue logrado en su justa medida por la Reina Isabel, utilizando el boato cuando se precisaba y ajustándose más a la modestia cuando la exaltación del poder real no era necesaria.

Las fiestas en la Corte y las aficiones de la reina merecerían un capítulo aparte, que en este escrito no vamos a tratar; solo destacar que hay anotadas partidas para bailes, destacando una en la que se otorgan 6.801 mrs en vestir a un bailador negro (Azcona, 1999: 376) o partidas para accesorios de mascotas, destacando entre ellas vestidos para cuatro perros que trajeron de Francia por un coste de 1.115 mrs., o 36 varas de sayal para

\footnotetext{
${ }^{18}$ No obstante, según recoge Luis Suárez, vistos los registros de ingresos de la Corona de Castilla, en 1477 se ingresaba en los reinos de Castilla y de León una cifra en torno a los 25,5 millones de maravedíes, alcanzando en el año del fallecimiento de Isabel la nada desdeñable cantidad de 341,7 (aprox.) millones de mrs.

${ }^{19}$ Así la retrata Juan de Flandes en la famosa obra conservada en el Palacio Real y que ha servido durante mucho tiempo para alimentar esa mitología de sobriedad que ha envuelto a la reina. Hay que tener en cuenta que este retrato está datado entre 1500 y 1504, por lo tanto, en los últimos años de vida de la soberana, cuando sus fuerzas físicas y emocionales (ya había sufrido todas las pérdidas familiares indicadas anteriormente) habían hecho mella en ella (a ello le unimos el inquietante futuro que se avecinaba a los reinos de Castilla y de León con la legítima sucesora, la infanta Juana). Qué diferente es este retrato del que aparece en la Virgen de los Reyes Católicos, obra aludida anteriormente, o en sus retratos de juventud.
} 
vestir a los gatos de algalia, por un importe total de 1.350 mrs (Azcona, 1999: 375). Parece quedar claro, por tanto, que la corte de la Reina Isabel no podría definirse precisamente como una corte austera y abstinente (y eso sin entrar en los gastos de la Cámara del rey Fernando o de los infantes).

- Mesura en la mesa, evitando la glotonería y la bebida en demasía: este aspecto lo llevó la reina hasta el extremo, especialmente en el beber, ya que hay constancia escrita de que nunca bebía vino, únicamente agua. Volviendo a Luján y sus Coloquios, se indica: "la muger no ha de beber vino [...] priva de sus sentidos y los torna locos y baxado y distilado de alli hincha las venas, entorpece los nervios”.

- Justicia, igualdad y afabilidad con sus súbditos: Este punto resulta altamente interesante. Aunque en el siglo XXI la obra de los Reyes Católicos resulta muy cuestionada, entre otros factores debido a la implantación de la Inquisición y a la expulsión de judíos y musulmanes de sus territorios, no hay que olvidar que el concepto que nosotros, en este siglo, tenemos de la justicia no es el mismo que el que se tenía en esa época. En el siglo XV la justicia tenía como inicio y fin a Dios; es decir, era la justicia divina la que determinada todas y cada una de las reprobaciones de las acciones, y los reyes, en nombre de Dios, la impartían. Sin ser mi deseo entrar en un tema harto complicado como es el de la Inquisición, objeto de estudio que no corresponde a este artículo, sí hay que recalcar que esta institución responde, en parte, a esa concepción legalista divina que existía en la época (todo aquel convertido a la fe verdadera que reniegue de ella, está atentando contra la esencia de esa fe). No obstante, la reina se rodeó entre sus más íntimos colaboradores de nuevos cristianos y de judíos (entre otros motivos porque estos eran hábiles comerciantes y llegaron a amasar importantes cantidades de dinero, hecho que causaba gran animadversión entre los viejos cristianos). Con esto se quiere hacer hincapié en que aunque nosotros podemos considerar como hechos reprobables muchos de los ocurridos en la época, no así se tenían en consideración entonces. Nuestro ideal de justicia no era el ideal de justicia del siglo XV; este resulta un punto fundamental para comprender la Historia sin caer en prejuicios y reflexiones morales que en nada ayudan a equilibrar el rigor histórico.

La Reina Isabel intermedió también en procesos de amparo a la mujer, como nos ilustra una Real Cédula emitida al inicio de su reinado (1478), en la que declara bajo su guarda y con carta de seguro a Isabel Díaz, de Sevilla, mujer de Bartolomé de Palma, de quien, por estar separados y él viviendo con otra mujer, temía que la matase ${ }^{20}$.

Igualmente, y en relación al amparo de invenciones, creó el antecedente de la patente al registrar la “ynvençion” de molinos de Pedro de Azlor (su físico), esgrimiendo la razón de que "si otra persona le oviere de tomar su ynvençion el perderia todo su trabajo [...] e resçibiria grand daño"21.

En cuanto a los habitantes de los nuevos territorios descubiertos (las Yndias), la reina siempre deseó su amparo y que recibieran un trato igualitario, como el resto de sus súbditos (aunque sus deseos no siempre fueron cumplidos una vez las naos cruzaban el

\footnotetext{
${ }^{20}$ Archivo General de Simancas. CCA.DIV. 42,8.

${ }^{21}$ Archivo General de Simancas. RGS-LEG 147802,26.
} 
océano). Así lo deja dictado en el codicilo de su testamento emitido el 23 de noviembre de 1504, en el que afirma

[...]por ende suplico al rey mi sennor muy afectuosamente, e encargo e mando a la dicha prinçesa, mi hija, e al dicho prínçipe, su marido, que así lo hagan e cunplan, e que este sea su prinçipal fin, e que en ello pongan mucho diligençia, e no consientan nin den lugar que los indios vezinos e moradores de las dichas Yndias e Tierra Firme, ganadas e por ganar, reçiban agravio alguno en sus personas ni bienes, más manden que sean bien e justamente tratados, e si algund agravio han reçebido lo remedien e provean por manera que no se exçeda en cosa alguna [...].

Así pues, Asimismo, dependiendo de los beneficios que se recibieran por parte de la Corona, sus súbditos podrían ser más o menos partidarios del concepto igualitario de justicia de la reina. En asuntos de la nobleza, la Corona siempre intentó una cierta equidad y practicar el perdón, especialmente con aquellos que formaron parte del bando portugués en la Guerra de Sucesión Castellana. En una carta fechada en 1480, Fernando e Isabel declaran: "avemos perdonado a todos [...] nuestros vasallos, súbditos en naturales que estavan con el dicho rey de Portogal” ${ }^{22}$. No obstante, no hay que olvidar que a los Reyes Católicos les convenía tener de su lado a los nobles (a los que también, a la postre, les rescindieron numerosos beneficios y el protagonismo del que habían gozado en reinados anteriores).

Con estas palabras no se pretende, en ningún caso, realizar una alabanza inconsciente y exacerbada de la labor de la Reina Isabel, porque, obviamente, ningún reinado puede gozar de tan alta estima sin encontrar mancha alguna en su recorrido. Isabel tenía muy claro cómo y en qué condiciones deseaba reinar, y que su linaje fuera recordado, y los diversos conceptos aquí expuestos formaron parte de la consecución de esos propósitos en un entorno social acorde a todos y cada de los acontecimientos que allí se sucedieron.

- Cultivo de la educación mediante la lectura de autores cristianos. En este sentido, la información aportada por los registros de la biblioteca de la reina, resulta clarificadora. Su infancia en Madrigal y Arévalo, recibiendo la formación cristiana por parte de su madre y de sus preceptores, actuó de barbecho para forjar su posterior personalidad adulta. Un capítulo interesante al respecto, y que comenta ampliamente Tarsicio de Azcona en su estudio crítico, es la relación de alabanza y exquisito estudio que Isabel mantuvo hacia la Orden de la Observancia de los franciscanos y hacia la de los dominicos (aunque sintiendo mayor predilección por los primeros). Ambas corrientes cristianas resultan ser su mayor fuente de inspiración a lo largo de todo su reinado.

Una vez resumidas en este punto las virtudes que ensalza Martín de Córdoba en la personalidad y buen hacer de la futura gobernante y que, como vemos, parecen proyectarse en las acciones futuras que emprendió Isabel, pasamos ahora al campo de los vicios que la gobernante debe evitar.

\footnotetext{
${ }^{22}$ Archivo General de Simancas. RGS,LEG,148006,33
} 


\subsection{Vicios femeninos}

- Charlatanería: Defecto que Martín de Córdoba ubica como propio del género femenino. Así también lo descubrimos en el Coloquio de Luján entre Dorotea y Eulalia, en la que la casada le indica a la soltera: "dos cosas pierden a la muger conviene saver, lo mucho que parla y lo muy poco que sufre [...]”.

Esta concepción de la mujer era, por tanto, habitual en la época (y en épocas anteriores). La Reina Isabel, por lo que nos narran las crónicas, cuidaba mucho de evitar ese vicio. No obstante, tampoco caía en el silencio perpetuo, otro de los inconvenientes que enumera el tratadista agustino y que tampoco parece relacionarse con el carácter de La Católica. Alonso de Palencia recoge como halago estas características de la soberana: "verla hablar era cosa divina el valor de sus palabras e con tanto e tan alto peso e medida que ni dezia mas ni menos de lo que hacia al caso de los negocios y a la calidad de la materia que trataba” (Ladero Quesada, 1999: 238).

- Codicia, apetito de riquezas, honores y deleites: Insistimos en que parte de las características de este epígrafe no encajaban correctamente con lo que un poder real debía representar. Así, en su imagen de poder, la reina era

muy ceremoniosa en los vestidos y arreos y en sus estrados y asientos en el servicio de su persona; y quería ser servida de hombres grandes y nobles, y con grande acatamiento y humillación [...] Y como quiera que por esta condición le era imputado algún vicio, diciendo ser pompa demasiada, pero entendemos que ninguna ceremonia en esta vida se puede hacer tan por extremos los reyes que mucho más no requiera el estado real, el cual así como es uno y superior en los reinos, así debe mucho extremarse y resplandecer sobre todos los otros estados, pues tiene autoridad divina en las tierras (Ladero Quesada, 1999: 266).

Sin duda reveladoras palabras que podrían estar dictadas por la reina como justificación del boato y exaltación de su imagen regia.

\section{CONCLUSIONES}

Por todo lo expuesto en las páginas previas, podemos afirmar que los dictámenes plasmados por Martín de Córdoba en su tratado Jardín de nobles doncellas acerca de cómo debía ser la personalidad y la actividad de una virtuosa joven doncella, son claramente visibles en la personalidad de Isabel la Católica a lo largo de toda su vida. Por lo tanto, válido resulta reseñar que nuestra hipótesis inicial sí puede ser ratificada: este tratado influyó en la personalidad y en el gobierno de la Reina Isabel.

Igualmente, una segunda hipótesis, secundaria al planteamiento inicial de este trabajo, permite hacer reflexionar sobre si este tratado formó parte de esa maquinaria propagandística a la que en tantas ocasiones hemos hecho referencia en este artículo, y que comenzó a engrasarse durante su última etapa como princesa, funcionando a la perfección a lo largo de todo su reinado.

Dicho esto, parece razonable plantearse si Martín de Córdoba escribió estas directrices en función de cómo consideraba él que debía ser Isabel cuando fuera reina, o, si fue la propia Isabel y sus preceptores de la época, los que estimularon la plasmación de esas cualidades (que a la postre sabían cumplidas) en el tratado estudiado. 
Teniendo en cuenta que las características de la joven doncella descrita por Martín de Córdoba en su obra encajan casi a la perfección con la personalidad de Isabel, parece razonable afirmar que este tratado formó parte de esa imagen de poder, de esa maquinaria propagandística que tanto ayudó al reinado de la reina Católica.

Asimismo, esta conclusión permitiría esclarecer por qué no se encontró ningún ejemplar de esta obra entre las catalogadas en la biblioteca isabelina; parece claro que una obra que sirviera como inspiración y no como instrumento político, debería haber ocupado un lugar preponderante en esa colección bibliográfica; y ésta no fue una de esas obras, al menos en el primer inventario bibliográfico realizado.

\section{REFERENCIAS BIBLIOGRÁFICAS}

Azcona, T. de (1999). Isabel la Católica. Estudio crítico de su vida y su reinado. Madrid: Biblioteca de autores cristianos.

Bernáldez, A. (1594). Crónica de los Reyes Católicos. En Biblioteca Nacional, recuperado de: http://bdh-rd.bne.es/viewer.vm?id=0000010015\&page=1

Codicilo de la Reina Isabel la Católica, otorgado en Medina del Campo, el 23 de noviembre de 1504 [Manuscrito bdh0000022770]. En Biblioteca Nacional, recuperado de: http://bdh-rd.bne.es/viewer.vm?id=0000022770\&page=1

Córdoba, M. de (1968). Jardín de nobles doncellas. En Prosistas castellanos del siglo XV (tomo II). Madrid: Biblioteca de Autores Españoles, tomo CLXXI.

Ladero Quesada, M.A. (1999). La España de los Reyes Católicos. Madrid: Alianza Editorial.

Luján, P. de (1550). Coloquios matrimoniales / del licenciado Pedro de Luxan En los quales se tracta, como se ha de auer entresi los Casados: y conseruar la paz. Criar sus hijos y gouernar su casa. Tocase muy agradables sentencias, dichos y hechos, leyes y costumbres antiguas... Sevilla. En Biblioteca Nacional, recuperado de: http://bdh-rd.bne.es/viewer.vm?id=0000240782\&page $=1$

Pelaz Flores, D. (2013). La imagen de la reina consorte como muestra de poder en el reino de Castilla durante el siglo XV. Construcción y significado. Medievalismo, 23, 265290.

Pulgar, H. de (Siglo XVI). Crónica de los Reyes Católicos con la continuación [Manuscrito]. En Biblioteca Nacional, recuperado de: http://bdhrd.bne.es/viewer.vm?id=0000073397\&page $=1$

Rábade Obradó, P. (2005). Ética y política: recomendaciones de Fray Martín Alonso de Córdoba a la futura Isabel I. En M.V. López Cordón \& G. Franco Rubio (Coords.), La Reina Isabel I y las reinas de España: realidad, modelos e imagen historiográfica, Actas de la VIII Reunión Científica de la Fundación Española de Historia Moderna (pp. 63-79). Madrid: Fundación Española de Historia Moderna.

Sánchez Dueñas, B. (2002). Una particular visión de la mujer en el siglo XV: Jardín de Nobles Doncellas de Fray Martín de Córdoba. Boletín de la Real Academia de Córdoba de Ciencias, Bellas Letras y Nobles Artes, 141, 291-300. 
Soriano del Castillo, C. (1997). Conveniencia política y tópico literario en el Jardín de nobles doncellas (1468) de Fray Martín Alonso de Córdoba. En J.M. Lucía Megías (Coord.), Actas del VI Congreso Internacional de la Asociación Hispánica de Literatura Medieval, vol. 2 (pp. 1457-1466). Alcalá de Henares: Universidad de Alcalá.

Suárez, L. (2012). Isabel I Reina. Madrid: Ariel. 